\title{
Paratuberculosis en rebaños caprinos chilenos
}

\author{
Paratuberculosis in Chilean dairy goat herds \\ J Kruze, ${ }^{1 *}$ M Salgado, ${ }^{1}$ M T Collins ${ }^{2}$ \\ ${ }^{1}$ Instituto de Microbiología, Facultad de Ciencias, Universidad Austral de Chile, Valdivia, Chile, \\ ${ }^{2}$ School of Veterinary Medicine, University of Wisconsin, Madison, USA
}

\begin{abstract}
SUMMARY
Paratuberculosis in goats is widely distributed throughout the world. Recently the disease has been officially reported in Chile. The purpose of this study was to determine the infection status of some dairy goat herds under two types of management systems (intensive and extensive) in different regions of Chile. Faecal samples were collected from 383 female goats $>2$ years old belonging to 8 dairy goat herds located in the Metropolitan Region (2), $9^{\text {th }}$ Region (5) and $10^{\text {th }}$ Region (1). Differences in routine management were not considered when selecting the herds. Faecal samples were collected via rectum, decontaminated with hexadecylpyridinium chloride (HPC) and antibiotics, cultured on Herrold's Egg Yolk Medium with mycobactin $\mathrm{J}$, and incubated at $37^{\circ} \mathrm{C}$ for up to nine months. The suspected colonies were confirmed by PCR (IS900) technology using specific primers for this pathogen $\left(\mathrm{P} 90^{+}\right.$and $\left.\mathrm{P} 1^{+}\right)$. Thirty five out of the 383 sampled goats were faecal culture positive $(9.1 \%)$, all of them belonging to only four herds. These infected herds were generally larger, intensively managed, and they systematically violated most management recommendations for paratuberculosis control, including the routine introduction of animals of unknown paratuberculosis tests status from herds of unknown Map infection status. The remaining four uninfected herds were extensively managed, did not import goats from other herds, and were located in geographical areas where no mixed grazing with other susceptible ruminant species took place, this being a possible risk factor for paratuberculosis. This study reports the presence of caprine paratuberculosis in Chile, in particular in those dairy goat herds that have introduced high producing milk breeds of animals to improve the genetic capacity of milk production. Therefore, any attempt to evaluate the risk of introducing the infection in a paratuberculosisfree area as the result of purchasing animals is worthwhile.
\end{abstract}

Palabras clave: paratuberculosis, caprinos, prevalencia, manejo.

Key words: paratuberculosis, caprine, prevalence, management.

\section{INTRODUCCION}

La paratuberculosis, o Enfermedad de Johne, es una enfermedad bacteriana producida por Mycobacterium avium subsp. paratuberculosis (Map), que afecta a rumiantes, principalmente bovinos, ovinos y caprinos, produciendo una enteritis crónica e incurable que termina irremediablemente con la muerte del animal (Forshell 2001). La paratuberculosis fue descrita por primera vez en Alemania por Johne y Frothingham (1895) en la especie bovina, en la cual la enfermedad ha sido muy bien caracterizada y está ampliamente difundida en la mayoría de los países, especialmente en rebaños lecheros. En Chile, la enfermedad fue descrita por primera vez en bovinos por Grinbergs y Caorsi (1958) en la provincia de Valdivia.

Al igual que en el bovino, la paratuberculosis en pequeños rumiantes está ampliamente distribuida en el mundo, siendo descrita por primera vez en caprinos por Twort e Ingram en Alemania (Twort e Ingram 1912). En

Aceptado: 01.08.2006.

* Correspondencia: jkruze@uach.cl, Casilla 167, Valdivia, Chile. los años siguientes, la paratuberculosis caprina fue descrita en muchos otros países tanto de Europa (Noel-Pillers 1924, Rossi 1928, Lysne 1963, Cottereau y col 1964, Leontides y col 1975, Csplo y col 1984, León y col 1984) como de Asia y Africa (Katic 1969, Chiodini 1993). En el continente americano, la paratuberculosis caprina ha sido descrita en EE.UU. (Eveleth y Eveleth 1943), Argentina (Ubach 1941), Canadá (Morin 1982) y México (Ramírez y col 1983). En Chile, el primer caso de paratuberculosis en pequeños rumiantes fue descrito por Zamora y col (1975) en ovinos, también en la provincia de Valdivia. Si bien es cierto existen algunos antecedentes para afirmar que la paratuberculosis caprina también está presente en el país (Abalos y col 2002), sólo recientemente la enfermedad ha sido descrita en caprinos lecheros, basado en antecedentes clínicos, histopatológicos, serológicos y bacteriológicos (cultivo y PCR), constituyendo el primer caso publicado en forma oficial en Chile (Kruze y col 2006).

A diferencia del bovino, los antecedentes sobre paratuberculosis ovina y caprina a nivel internacional son escasos y mucho de lo que se sabe respecto a transmisión y respuesta inmune del huésped en estas especies se asume que es similar a la del ganado bovino. Sin embargo, existen algunas diferencias importantes especialmente 
en relación a las características del agente etiológico, signos clínicos e histopatología (Stehman 1996).

Aunque la prevalencia real de paratuberculosis en la población caprina de Chile es desconocida, actualmente existe gran interés entre los productores caprinos en conocer el estado de infección de sus rebaños, con el objeto de implementar las medidas apropiadas para su control, especialmente por el eventual riesgo potencial del agente etiológico en la especie humana. En consecuencia, el objetivo del presente estudio fue determinar el estado de infección de algunos rebaños caprinos lecheros y la frecuencia de animales positivos en diferentes regiones del país y bajo diferentes sistemas de manejo del rebaño.

\section{MATERIAL Y METODOS}

Rebaños y animales. El estudio se realizó durante los meses de octubre 2004 y enero de 2005, en 8 rebaños lecheros ubicados en la Región Metropolitana (2), IX Región (5) y X Región (1). Para asegurar la detección de un mayor número de individuos infectados dentro de cada rebaño, se seleccionaron sólo animales $>2$ años de edad, o con al menos 2 partos, incluyendo rebaños con y sin antecedentes históricos de la enfermedad, basado en registros clínicos y/o de laboratorio proporcionado por los propietarios. Para la selección de los rebaños no se consideraron diferencias en las rutinas de manejo entre cada rebaño, como tampoco cualquier otro factor que pudiera influir el estado bacteriológico de cada unidad productiva. En total se seleccionaron 383 animales para examen bacteriológico (cultivo fecal) y las principales características de los 8 rebaños seleccionados eran las siguientes:

Rebaño 1: ubicado en la comuna de Lampa (Región Metropolitana), con una masa total de 500 animales y 220 hembras en ordeña; manejo intensivo con estabulación permanente, ordeña mecánica, sistema de registros de producción, edad, genético y alimentación. Explotación con 15 años de existencia y libre de brucelosis y tuberculosis. En el año 1996 se realizó un ELISA para diagnosticar paratuberculosis, resultando 4 animales positivos. En el año 2001 se repitió el mismo examen y se obtuvieron 10 animales positivos. Durante la visita se observaron alrededor de 25 animales caquécticos sin causa nutricional aparente y se obtuvieron antecedentes de muertes previas de este tipo de animales con signos de marcado deterioro de la condición corporal, presencia de edema (hipoproteinemia), materia fecal pastosa e incluso diarrea. El rebaño fue formado con animales de raza Saanen importados desde países con mayor tradición caprina lechera y genética más desarrollada para producción de leche, pero también con presencia de la enfermedad. Además, se observaron casos clínicos sospechosos de linfoadenitis caseosa. Se tomaron muestras de 60 animales (12\%).
Rebaño 2: ubicado en la comuna de Buin (Región Metropolitana), compuesto de 150 animales masa con 60 en ordeña; caracterizado por un manejo intensivo con estabulación permanente, con ordeña mecánica y gran aporte de concentrado en la dieta; uso de registros de identificación, origen, fecha de nacimiento, genético y reproductivo; sin historial diagnóstico de paratuberculosis, aunque se informó de eventuales casos clínicos de animales de raza Anglonubia importados desde Nueva Zelanda. Debido al manejo alimentario del rebaño, la mayoría de los animales presentaba una condición corporal aceptable; sin embargo, se observaron algunas cabras con baja condición corporal. Se tomaron muestras de 58 animales (39\%).

Rebaño 3: ubicado en la comuna de Curacautín (IX Región). Rebaño compuesto de 51 animales con 30 cabras en ordeña; manejo de tipo extensivo con sistema de pastoreo directo rotacional; sin registros ni infraestructura especializada y con ordeño manual. Rebaño formado con animales criollos comprados en predios de la comuna de Lonquimay. Se muestrearon 32 animales (63\%).

Rebaño 4: ubicado en la comuna de Lonquimay (IX Región), compuesto de 115 animales con sólo 30 en ordeña; manejo de tipo extensivo con pastoreo directo rotacional; sin separación de las crías de sus madres y sin registros; infraestructura para estabulación nocturna y sala de ordeña con ordeño manual (figura 1). Sin antecedentes de la enfermedad ni exámenes previos. Se tomaron muestras de 35 animales (30\%).

Rebaño 5: ubicado en la comuna de Lonquimay (IX Región), con una masa de 111 animales y 100 en ordeña; manejo extensivo con pastoreo directo rotacional y con infraestructura especial para estabulación nocturna y sala de ordeña con uso de ordeña mecánica; hay separación de la cría de la madre con reunión 2 veces por día para su amamantamiento. Sin registros y sin antecedentes de paratuberculosis ni de exámenes previos. Se tomaron muestras de 54 animales (49\%).

Rebaño 6: ubicado en la comuna de Lonquimay (IX Región), con una masa de 100 animales y 40 en ordeña; manejo de tipo extensivo con pastoreo directo rotacional y sin infraestructura especializada; las crías no se segregan de las madres y no existen registros ni antecedentes de la enfermedad ni diagnósticos previos. Se tomaron muestras de 20 animales (20\%).

Rebaño 7: ubicado en la comuna de Lonquimay (IX Región), compuesto de 160 animales masa y 90 en ordeña; manejo intensivo con estabulación permanente e infraestructura para ordeña mecánica (figura 2); buen sistema de registros de producción, edad, genético y alimentación. Rebaño formado hace 4 años con animales importados de un rebaño experimental de alta producción ubicado en la Región Metropolitana, con un reconocido estado de infección con Map. Los registros indican frecuente presentación de casos clínicos con animales de baja condición corporal, pérdida progresiva de 
peso, diarrea oscura, sin recuperación posterior a tratamiento con antibióticos y, finalmente, muerte. Existe, además, el antecedente de alta prevalencia de casos clínicos de linfoadenitis caseosa. El último año las crías se alimentaron con leche en forma directa. Se tomaron muestras de 94 animales (59\%).

Rebaño 8: ubicado en la comuna de Purranque (X Región), compuesto de 75 animales masa y 42 en ordeña; manejo intensivo con registros de edad, número de partos y producción; pastoreo dirigido con estabulación nocturna y ordeña mecánica. Sin antecedentes previos de la enfermedad. Durante la visita se observó un marcado deterioro de la condición corporal de los animales ( $\sin$ causa nutricional aparente), abortos, presencia de diarrea y edad avanzada de algunos animales. Se tomaron muestras de 41 animales $(55 \%)$

Diagnóstico. El estado de infección de los rebaños se determinó mediante cultivo fecal, método más utilizado para el diagnóstico de paratuberculosis en caprinos (Collins 1996). Las muestras de heces fueron obtenidas por vía rectal y transportadas al laboratorio en bolsas plásticas individuales para ser procesadas el mismo día de su recolección, previa descontaminación con cloruro de hexadecilpiridinio y antibióticos (amfotericina B, vancomicina y ácido nalidíxico). Para el aislamiento de Map se utilizó el medio de Herrold con yema de huevo (HEYM), suplementado con micobactina J y antibióticos (amfotericina B, vancomicina y ácido nalidíxico), siguiendo las recomendaciones del laboratorio de diagnóstico de la Universidad de Cornell, USA (Stabel 1997), empleando para cada muestra 3 tubos HEYM con micobactina y un tubo HEYM sin micobactina. Los cultivos fueron incubados a $37{ }^{\circ} \mathrm{C}$ en aerobiosis durante 9 meses y examinados semanalmente para detectar el desarrollo de colonias. Las colonias sospechosas de Map

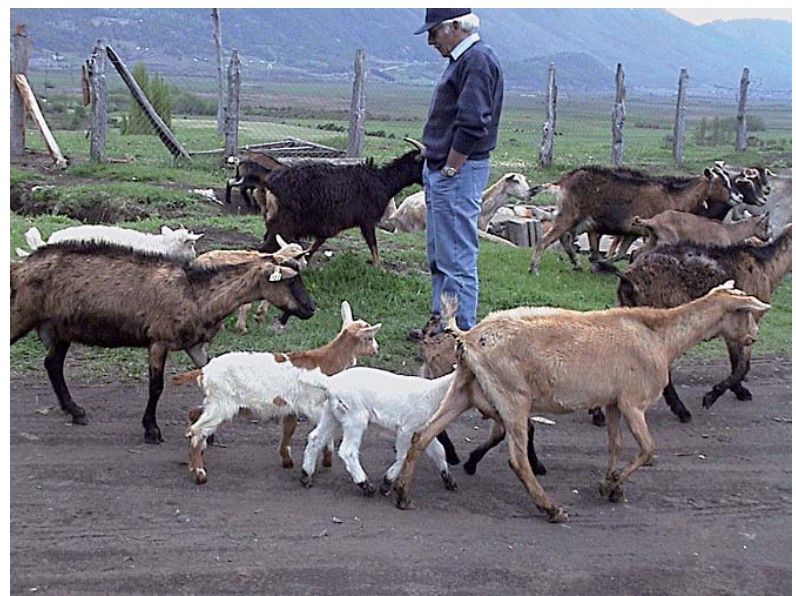

Figura 1. Caprinos de razas criollas típicas de un rebaño con manejo extensivo en el sur de Chile.

Typical local goat breeds in an extensive management herd system in southern Chile. (morfología típica de la colonia, crecimiento lento y micobactina dependiente) fueron confirmadas posteriormente por IS900 PCR utilizando partidores específicos para este patógeno $\left(\mathrm{P} 90^{+}\right.$y $\left.\mathrm{P}^{+} 1^{+}\right)$(Soto y col 2002).

Definición de caso. La definición de caso para cabras infectadas con Map fue el aislamiento del agente a partir de la muestra fecal. La definición de caso para una cabra no infectada fue cualquier cabra proveniente de un reba-

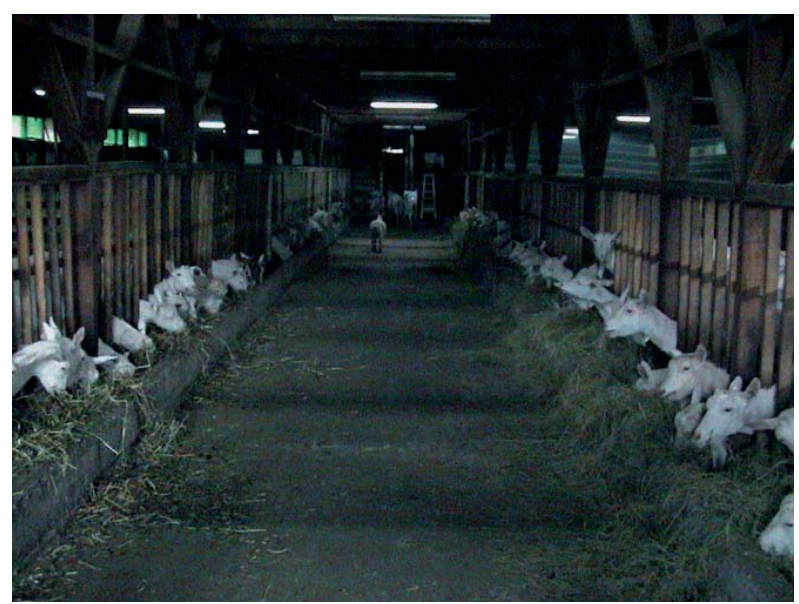

Figura 2. Caprinos de razas especializadas en producción de leche en un rebaño con manejo intensivo en el sur de Chile.

High milk producing dairy goats in an intensive management herd system in southern Chile.

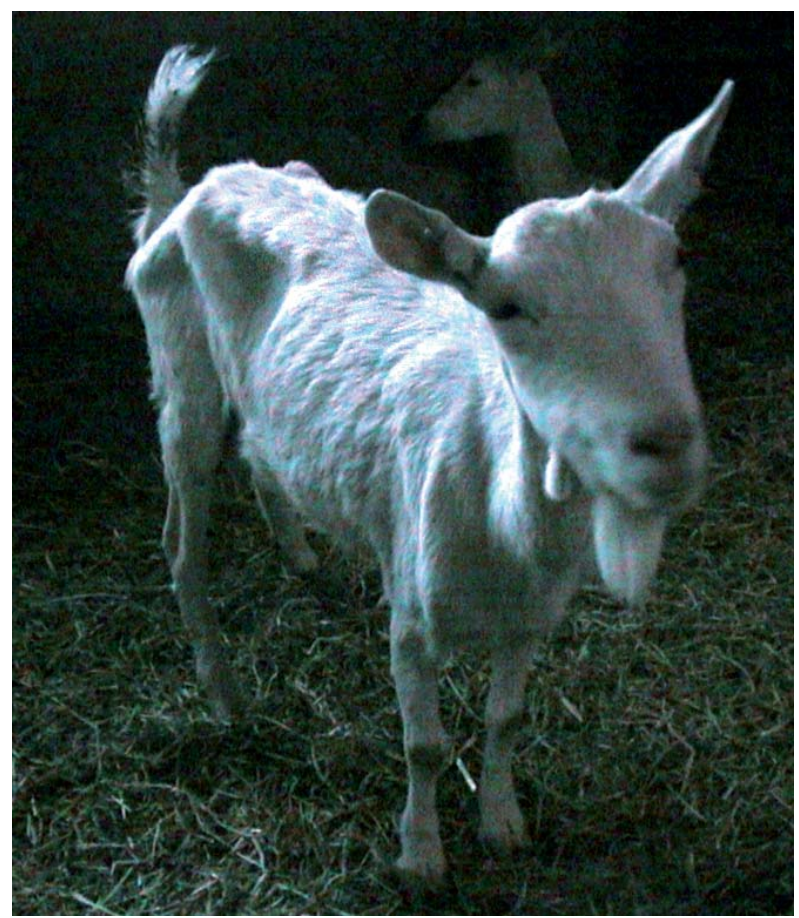

Figura 3. Caso clínico: cabra con pobre condición corporal, baja producción de leche y caquéctica en un rebaño infectado. Clinical case: goat with poor body condition, low milk production, and cachexia in an infected herd. 
ño libre de paratuberculosis (rebaño con $100 \%$ de cultivos fecales negativos).

\section{RESULTADOS Y DISCUSION}

El 50\% (4) de los rebaños y el 9,1\% (35) de los animales examinados resultaron positivos al cultivo fecal, provenientes todos de rebaños con manejo intensivo y presencia de razas importadas (cuadro 1). Todos los cultivos sospechosos de Map resultaron positivos a la confirmación por PCR IS900.

La población caprina en Chile es ligeramente superior a 700.000 cabezas concentradas fundamentalmente en la IV Región (42\%) con sólo un $27 \%$ en la IX y X Regiones (González 1998). El 80\% de estos caprinos corresponde a animales criollos provenientes de cruces con cabras originarias de España y otras de origen norteeuropeo, situación que explica la gran variabilidad genética existente, incluso dentro de un mismo rebaño. A diferencia de lo que ocurre con la paratuberculosis bovina, existe escasa información respecto a la enfermedad en la especie caprina desconociéndose tanto su prevalencia como su impacto económico en la industria láctea nacional, situación que es muy similar a la de otros países. Sin embargo, un estudio realizado en Noruega detectó un 50\% de rebaños infectados y una tasa de infección individual entre $4,7 \%$ y $9,0 \%$ en caprinos beneficiados en matadero en un período de 15 años (Saxegaard y Fodstad 1985). Otro estudio realizado en EE.UU. en 6 rebaños de California con una masa total de 238 caprinos determinó un 33,3\% de rebaños infectados detectados por cultivo fecal y una prevalencia individual promedio de $3 \%$ con un rango de 6-10\%, siendo los animales más viejos los más infectados (West y col 1979). El único estudio de prevalencia realizado previamente en Chile, sobre un universo de 2.500 cabras lecheras de rebaños con producción intensiva de la zona central del país, determinó una seroprevalencia individual de 9,3\% (Pinto y col 2002), resultado muy similar al encontrado en el presente estudio (cuadro 1), aunque estos autores no realizaron cultivo fecal. Nuestros resultados concuerdan, además, con lo reportado por Saxegaard y Fodstad (1985) y West y col (1979), quienes sí utilizaron cultivo fecal.

Es importante destacar la estrecha asociación observada en el presente estudio entre el sistema de manejo de los rebaños y el estado de infección de los animales. En efecto, todos los rebaños infectados se caracterizaban por un sistema de manejo intensivo y de alta producción (cuadro 1), sin medidas de control ni estrategias de diagnóstico, lo que permitiría explicar la mayor tasa de animales positivos al cultivo fecal. Además, estos resultados son consistentes con los antecedentes históricos de cada rebaño respecto a presentación de casos clínicos, resultados serológicos, cultivos positivos e incluso tasa de mortalidad en alguno de ellos. Una característica epidemiológica común en los cuatro rebaños infectados era que no practicaban medidas de manejo para prevenir la infección de los animales jóvenes, especialmente los recién nacidos, que son los más susceptibles. De acuerdo con Collins (1994), estas medidas básicas incluyen limpieza de las áreas de parto y separación del recién nacido de su madre lo antes posible, alimentación de las crías con calostro de hembras comprobadamente negativas a Map, uso de sustituto lácteo o leche pasteurizada, eliminación de animales comprobadamente infectados, manejo de los animales recién nacidos lejos del contacto con materia fecal de animales adultos, y evitar la contaminación de los alimentos con material fecal de animales adultos. En consecuencia, es posible asumir que estos factores fueron las razones más probables que explicarían la perpetuación de la infección en estos rebanos junto con la falta de una política de control y erradicación de la enfermedad. Sin embargo, es necesario analizar también uno de los factores epidemiológicos más importantes relacionado con la introducción de la infección en un rebaño libre. Al respecto, no existe duda alguna que la compra o introducción de animales infectados con Map, o con estado incierto de infección, es la principal vía de diseminación de Map entre los rebaños (Sweeney 1996, Kennedy y Benedictus 2001). Esta práctica también era común para todos los rebaños infectados, ya que se comprobó que todos ellos, directa o indirectamente, habían importado animales de genética seleccionada para aptitud lechera de países cuyo estatus de infección es ampliamente reconocido, lo que permitiría concluir que la infección habría sido importada a Chile con los animales, situación que fue ignorada, por desconocimiento tal vez, por los planteles que sirvieron de núcleo de mejoramiento genético en el país. Por el contrario, los 4 rebaños de la IX Región con la totalidad de los animales negativos al cultivo fecal, y supuestamente libres de infección, eran rebaños con manejo más extensivo, formado con razas criollas sin participación de reproductores importados de otros planteles y están ubicados en áreas geográficas donde no se explotan otras especies de animales rumiantes susceptibles a Map. En estos rebaños, el diagnóstico y las prácticas de manejo para el control de la enfermedad no serían tan importantes como el área geográfica para explicar la condición de rebaños libres. Para algunos autores, este último aspecto cobra especial importancia en rebaños con manejo extensivo, debido a que el pastoreo en áreas comunes por diferentes especies animales es una gran oportunidad para diseminar la infección. Así, por ejemplo, Ris y Weaver (1988), en Nueva Zelanda, aislaron Map de tejido intestinal en 6 de 9 cabras de un año de edad de un plantel manejado con sistema de pastoreo rotacional inmediatamente después del pastoreo con ganado bovino infectado.

Los resultados del presente estudio permiten concluir que la paratuberculosis en rebaños caprinos en Chile está distribuida en una amplia zona geográfica y que, en aque- 
Cuadro 1. Número de animales muestreados y porcentaje de cultivo fecal (CF) positivo a Map en rebaños caprinos chilenos.

Number of animals sampled and percentage of Mappositive faecal culture (FC) in Chilean goat herds.

$$
\mathrm{N}^{\circ} \quad \mathrm{N}^{\mathrm{o}}
$$

Rebaño/Comuna/Región analizados CF-positivo Porcentaje

\begin{tabular}{llrc}
\hline & & & \\
1 Lampa / RM* & $60 / 500$ & 14 & 23,3 \\
2 Buin / RM & $50 / 150$ & 6 & 12 \\
3 Curacautín / IX & $31 / 51$ & 0 & 0 \\
4 Lonquimay / IX & $34 / 115$ & 0 & 0 \\
5 Lonquimay / IX & $53 / 111$ & 0 & 0 \\
6 Lonquimay / IX & $20 / 100$ & 0 & 0 \\
7 Lonquimay / IX & $94 / 160$ & 10 & 10,6 \\
8 Purranque / X & $41 / 75$ & 5 & 12,2 \\
\hline
\end{tabular}

* Región Metropolitana.

llos con alta prevalencia de infección, ocasiona cuantiosas pérdidas económicas por pérdida de peso (figura 3), menor producción, eliminación prematura y muerte de animales. Además, los rebaños libres de infección detectados en la IX Región podrían ser considerados como un núcleo de referencia para futuros estudios de validación de pruebas diagnósticas, asumiendo una especificidad diagnóstica de $100 \%$ para el cultivo fecal.

Debido a las características epidemiológicas de la enfermedad, los programas de control de paratuberculosis son complejos, de alto costo y a largo plazo, y requieren de pruebas diagnósticas eficientes para detectar el mayor número posible de animales infectados. Si a estos aspectos se suma la falta de familiaridad de los productores con la enfermedad, la ausencia de programas de control y regulación del movimiento de animales a nivel regional y nacional, es posible esperar que la paratuberculosis continúe diseminándose en los rebaños caprinos de Chile.

\section{RESUMEN}

La paratuberculosis caprina está ampliamente distribuida a nivel mundial y recientemente la enfermedad ha sido oficialmente reportada en Chile. El objetivo de este estudio fue determinar el estado de infección de algunos rebaños caprinos lecheros en diferentes regiones del país y bajo dos sistemas de manejo, intensivo y extensivo.

Se analizaron muestras de material fecal de 383 animales $>2$ años de edad provenientes de 8 rebaños lecheros ubicados en la Región Metropolitana (2), IX Región (5) y X Región (1). Para la selección de los rebaños no se consideraron diferencias en las rutinas de manejo. Las muestras de materia fecal se recolectaron por vía rectal y, previa descontaminación con HPC y antibióticos, se cultivaron en medio de Herrold con yema de huevo y micobactina J, por un período máximo de 9 meses. Las colonias sospechosas de Map fueron confirmadas por PCR (IS900) utilizando partidores específicos para este patógeno

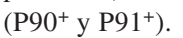

Del total de animales muestreados, $35(9,1 \%)$ resultaron positivos al cultivo fecal, provenientes todos de sólo 4 rebaños cuya característica común era que no practicaban medidas de manejo para prevenir la infección de los animales jóvenes y habían importado animales de alta producción y selección genética. Por el contrario, los rebaños no infectados se caracterizaban por un manejo más extensivo, formado sólo por razas criollas con un núcleo de reproductores cerrado y están ubicados en áreas geográficas donde no se explotan otras especies de animales rumiantes susceptibles a Map.

El presente estudio permite confirmar que la paratuberculosis caprina está presente en Chile, especialmente en aquellos rebaños que han introducido al país animales de alta genética lechera. Por lo tanto, es necesario evaluar el riesgo de introducir la infección en un área libre antes de comprar animales para mejorar la producción del rebaño, realizando un diagnóstico previo en los planteles de origen.

\section{AGRADECIMIENTOS}

Al Instituto de Microbiología, Facultad de Ciencias, Universidad Austral de Chile por el apoyo financiero para realizar este estudio.

\section{REFERENCIAS}

Abalos P, A Rojas, P Retamal. 2002. Diagnóstico de paratuberculosis en un rebaño caprino de la IV Región, Chile. Resúmenes del XII Congreso Nacional de Medicina Veterinaria, Chillán, Chile. (CD).

Collins MT. 1994. Clinical approach to control of bovine paratuberculosis. J Am Vet Med Assoc 204, 208-210.

Collins MT. 1996. Diagnosis of Paratuberculosis. Vet Clin North Am Food Anim Pract 12, 357-371.

Cottereau P, A Poulenard, M Poulenard. 1964. Un cas de paratuberculose chez la chèvre. Bull Soc Sci Vet Med Comp Lyon 66, 351-355.

Csplo A, B Kormendy, T Benda. 1984. Paratuberculosis in goats of the Cameronian breed. Magyar Allt Lapja 39, 667-669 (abstract).

Chiodini RJ. 1993. The history of paratuberculosis (Johne's disease). A review of the literature 1985 to 1992. The International Association for Paratuberculosis, Inc., Providence, RI, USA, Pp 658.

Eveleth MW, DF Eveleth. 1943. Johne's disease of goats. Vet Med 38, 258-261.

Forshell KP. 2001. Description of Paratuberculosis. International Dairy Federation, Brussels, Belgium. FIL/IDF Bull 364, 9-12.

González C. 1998. Desarrollo caprino en la Región de Coquimbo: Antecedentes y análisis. Citado en "Caprinos de leche en Chile: situación actual y perspectivas", FIA, Ministerio de Agricultura, Chile, 1999, Pp 63.

Grinbergs J, I Caorsi. 1958. Enfermedad de Johne o Paratuberculosis en Chile. Publicaciones Científicas de la Universidad Austral de Chile. 4, 9-13.

Johne HA, J Frothingham. 1895. Ein eigenthuemlicher fall von tuberculose beim rind. Dtsch tiermed Pathol 21, 438-454. Citado por Stabel JR. 1998. Symposium: Biosecurity and disease, Johne's Disease: a hidden threat. J Dairy Sci 81, 283-288.

Katic I. 1969. Bibliography of literature on Johne's disease (Paratuberculosis) 1895-1964. The Royal Veterinary and Agricultural University, Copenhagen, Denmark, Pp 162.

Kennedy D, G Benedictus. 2001. Control of Mycobacterium paratuberculosis in agricultural species. Rev Sci Tech Off Int Epiz. 20, 151-179.

Kruze J, M Salgado, E Paredes, A Mella, MT Collins. 2006. Goat paratuberculosis in Chile: first isolation and confirmation of Mycobacterium avium subsp paratuberculosis infection in a dairy goat. J Vet Diagn Invest 18 (5) (en prensa).

León L, F Garrido, A Pardo, M Hermoso de Mendoza, J Carranza. 1984. Paratuberculosis in goats in southern Spain. Arch Zootec 33, 205-207 (abstract). 
Leontides S, D Tomopoulus, C Christopoulus, T Tsangaris, G Exarchopoulus. 1975. Paratuberculosis in goats in Greece. World Vet Congress, Thessaloniki, Greece, Summaries 2, 609-611.

Lysne I. 1963. Paratuberkulosen pa geitene vare. Medlemsbl Norske Vet Foren 15, 257-264.

Morin M. 1982. Johne's disease (Paratuberculosis) in goats: a report of eight cases in Quebec. Can Vet J 23, 55-88 (abstract).

Noel-Pillers AW. 1924. Johne's disease in the goat. J Comp Pathol Ther 80, 170-172.

Pinto J, L Maier, C Ríos, R Martínez. 2002. Prevalencia y factores de riesgo de paratuberculosis en sistemas productivos intensivos caprinos de la zona central de Chile. Resúmenes del XII Congreso Nacional de Medicina Veterinaria, Chillán, Chile (CD).

Ramírez PC, GV Tenorio, EG Valero, CC Ramírez, EE Trigo, F Prado, AE Díaz. 1983. Serological survey of sheep and goats in Mexico for paratuberculosis. Rev Latinoamer Microbiol 25, 56 (abstract).

Ris D, A Weaver. 1988. Natural transmission of Johne's disease to feral goats. $N Z$ Vet $J 36,98$.

Rossi L. 1928. Sur le enterite paratuberculeuse hipertrophiante de la chèvre. Bull Acad Vet Fr 1: 376-378.

Saxegaard F, FH Fodstad. 1985. Control of paratuberculosis (Johne's disease) in goats by vaccination. Vet Rec 20, 439-441.
Soto JP, J Kruze, S Leiva. 2002. Aislamiento de Mycobacterium avium subsp paratuberculosis de fecas en rebaños lecheros infectados mediante el Método de Cornell Modificado. Arch Med Vet 34: 275-282.

Stabel JR. 1997. An improved method for cultivation of Mycobacterium paratuberculosis from bovine fecal samples and comparison to three other methods. $J$ Vet Diagn Invest 9, 375-380.

Stehman SM. 1996. Paratuberculosis in small ruminants, deer, and south american camelids. Vet Clin North Am Food Anim Pract 12, 441-455.

Sweeney RW. 1996. Transmission of paratuberculosis. Vet Clin North Am Food Anim Pract 12, 305-312.

Twort FW, GLY Ingram. 1912. A method for isolating and cultivating Mycobacterium enteritidis chronicae pseudotuberculosae bovis, Johne, and some experiments on the preparation of a diagnostic vaccine for pseudotuberculous enteritis of bovines. Vet J 68, 353-365.

Ubach FA. 1941. Observaciones sobre la enfermedad de Johne y la enteritis coccidiósica de los bovinos, ovinos y caprinos identificadas en la República Argentina. Rvta Med Vet Bs Aires 23, 3-45.

West G, M Agbo, P Willeberg, R Ruppanner, O Aalund, D Behymer. 1979. Paratuberculosis in California dairy goats. Calif Vet 33, 28-31.

Zamora J, J Kruze, C Schifferli. 1975. Paratuberculosis ovina. Primer caso descrito en Chile. Arch Med Vet 7, 15-17. 